\title{
CASE REPORT - ACUPUNCTURE TREATMENT IN PATIENT WITH HORMONAL IMBALANCE
}

\author{
Blagica Arsovska ${ }^{1,2}$, Jihe Zhu ${ }^{1}$ and Kristina Kozovska ${ }^{1,3}$ 厑 \\ ${ }^{1}$ Faculty of Medical Sciences, University Goce Delchev, Shtip, Republic of Macedonia \\ ${ }^{2}$ Institute of Biology, Faculty of Natural Sciences and Mathematics, Skopje, Republic of Macedonia \\ ${ }^{3}$ Medicine Faculty, St. Cyril and Methodius University of Skopje, Republic of Macedonia
}
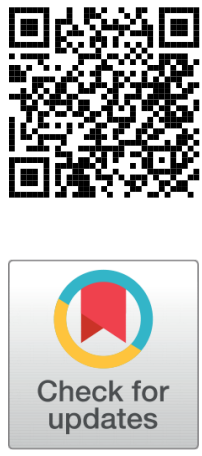

Received 6 June 2021

Accepted 18 June 2021

Published 30 June 2021

Corresponding Author

Kristina Kozovska, tongdatang-tc

m@hotmail.com

DOI $10.29121 /$

granthaalayah.v9.i6.2021.4046

Funding: This research received no specific grant from any funding agency in the public, commercial, or not-for-profit sectors.

Copyright: (C) 2021 The Author(s). This is an open access article distributed under the terms of the Creative Commons Attribution License, which permits unrestricted use, distribution, and reproduction in any medium, provided the original author and source are credited.

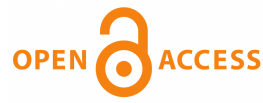

\section{ABSTRACT}

Hormones play a big role and are a huge part of women's health, including physically, mentally and emotionally. If the body produces too little or too much of some certain hormones, then the hormonal imbalance occurs. According to TCM, two organs mainly connected to the hormonal imbalances are the Kidney and the Liver. The aim of the TCM treatment for hormonal imbalance is to balance the Yin and Yang energy in the organs and the body and restore the Jing. In this research is presented a case of a 34 year old woman presented with reduced function of the thyroid gland and hormonal imbalance. Before starting the treatment the results are showing increased levels of TSH $(8.08 \mathrm{mIU} / \mathrm{ml})$, LH $(12.30 \mathrm{mIU} / \mathrm{ml})$ and FSH $(15.70 \mathrm{mIU} / \mathrm{ml})$ and decreased levels of fT4 $(9.78$ $\mathrm{pmol} / \mathrm{L})$. After the treatment the TSH $(2.79 \mathrm{mIU} / \mathrm{ml})$, fT4 $(14.00 \mathrm{pmol} / \mathrm{L})$ and LH $(7.93 \mathrm{mIU} / \mathrm{ml})$ were normalized and FSH $(12.20 \mathrm{mIU} / \mathrm{ml})$ was decreased with only 7 treatments within 7 weeks. Acupuncture points used in the treatment are: DU4 (MingMen), DU14 (DaZhui), DU20 (BaiHui), RN6 (QiHai), RN4 (QuanYuan), BL15 (XinShu), BL20 (PiShu), GB20 (FengChi), ST9 (RenYing), LI4 (HeGu), BL23 (ShenShu), LR2 (TaiChong), SP6 (SanYinJiao), ST36 (ZuSanLi), SP9 (YinLingQuan), KI3 (TaiXi) and Ashi points located on the neck (front and back). Acupuncture as part of the TCM can effectively help the patients struggling with hormonal imbalances to balance and regulate the hormones and harmonize the metabolism, nervous, reproductive and endocrine system.

Keywords: Traditional Chinese Medicine, Acupuncture, Endocrinology, Hormones, Imbalance

\section{INTRODUCTION}

Hormones play a big role and are a huge part of women's health, including physically, mentally and emotionally. Hormones normally change over time during pregnancy or menopause. If the body produces too little or too much of some certain hormones, 
then the hormonal imbalance occurs. In Traditional Chinese Medicine (TCM) it is explained as Yin and Yang imbalance.

Symptoms of hormonal imbalance are: irregular period, acne, PCOS, fatigue, mood changes, low energy, weight gain, anxiety, depression, insomnia, infertility, low sex drive, food cravings, digestive problems and other. The imbalance doesn't occur overnight and it always takes some time for the symptoms to become visible.

External factors that have an impact on the hormonal imbalance are: stress, excessive exercising, unhealthy diet, smoking, excessive caffeine and other.

TCM has more natural and holistic way of treating the diseases. The goal of the TCM treatment is to find and treat the root cause of the hormonal imbalance, providing a long lasting relief from the symptoms.

According to TCM, two organs mainly connected to the hormonal imbalances are the Kidney and the Liver. The Essence (Jing) is stored in the Kidney and is in charge and responsible for regulating the hormones and nourishing the organs, tissues and cells. The Liver is responsible for the emotions and the metabolism. If the Liver does not function properly, the hormones cannot be processed efficiently and the body becomes in hormonal imbalance. Therefore, the aim of the TCM treatment for hormonal imbalance is to balance the Yin and Yang energy in the organs and the body and restore the Jing.

Except acupuncture, other TCM treatments that can be used in hormone balancing are cupping and herbal medicine. The treatments also have a lot of benefits for the endocrine system by balancing the Yin/Yang energy, reducing the pain and promoting and stimulating fresh Qi and blood flow through the body.

Because the treatment is natural and very gentle, it takes some for the hormones and endocrine system to achieve balance. Clinics (2021)

\section{CASE REPORT}

In this research is presented a case of a 34-year-old woman presented with reduced function of the thyroid gland and hormonal imbalance. Symptoms that were present are: weight gain, fatigue, low energy, depression, hair loss, poor memory and concentration. The patient was presented with normal menstrual cycle, normal appetite and blood pressure.

The condition started a few months before starting the acupuncture treatments. The patient was taking Eutirox $0.25 \mathrm{mg}$ per day and anti-depressives.

The patient has done 7 acupuncture treatment, once weekly in a period of 7 weeks. The acupuncture treatments were made in a clinic for TCM and acupuncture in Skopje, North Macedonia by a doctor specialist in acupuncture. Treatments were done once a week, with duration of 30-45 minutes each side of the body. Treatments were done indoor, on a room temperature. In the treatment were used fine sterile disposable needles sized $0.25 \times 25 \mathrm{~mm}$ produced by Wuijuiang City Medical \& Health Material Co., LTD. 
Acupuncture points used in the treatment are: DU4 (MingMen), DU14 (DaZhui), DU20 (BaiHui), RN6 (QiHai), RN4 (QuanYuan), BL15 (XinShu), BL20 (PiShu), GB20 (FengChi), ST9 (RenYing), LI4 (HeGu), BL23 (ShenShu), LR2 (TaiChong), SP6 (SanYinJiao), ST36 (ZuSanLi), SP9 (YinLingQuan), KI3 (TaiXi) and Ashi points located on the neck (front and back).

Before and after the treatments were made two blood tests. The results are presented in Table 1.

Table 1 Blood test results from before and after the treatment

\begin{tabular}{|c|c|c|c|c|c|c|}
\hline $\begin{array}{l}\text { Analy- } \\
\text { sis }\end{array}$ & TSH & fT4 & LH & FSH & Prolactin & Estradiol \\
\hline 20.01.2: & 8.08 & 9.78 & 12.30 & 15.70 & 9.33 & 61.50 \\
\hline 16.03.2: & 2.79 & 14.00 & 7.93 & 12.20 & 6.35 & 71.20 \\
\hline $\begin{array}{c}\text { Ref } \\
\text { value }\end{array}$ & $\begin{array}{l}0.46-4.6 \\
\mathrm{mIU} / \mathrm{ml}\end{array}$ & $\begin{array}{c}11.5-22.7 \\
\mathrm{pmol} / \mathrm{L}\end{array}$ & $\begin{array}{c}1.98-11.0 \\
\mathrm{mIU} / \mathrm{ml}\end{array}$ & $\begin{array}{c}1.98-11.6 \\
\mathrm{mIU} / \mathrm{ml}\end{array}$ & $\begin{array}{c}3.2-24.3 \\
\mathrm{ng} / \mathrm{ml}\end{array}$ & $\begin{array}{c}26.5-161.0 \\
\mathrm{pg} / \mathrm{ml}\end{array}$ \\
\hline
\end{tabular}

Before starting the treatment the results are showing increased levels of TSH (8.08 $\mathrm{mIU} / \mathrm{ml}), \mathrm{LH}(12.30 \mathrm{mIU} / \mathrm{ml})$ and FSH $(15.70 \mathrm{mIU} / \mathrm{ml})$ and decreased levels of fT4 (9.78 pmol/L). After the treatment the TSH $(2.79 \mathrm{mIU} / \mathrm{ml})$, fT4 $(14.00 \mathrm{pmol} / \mathrm{L})$ and LH $(7.93 \mathrm{mIU} / \mathrm{ml})$ were normalized and FSH $(12.20 \mathrm{mIU} / \mathrm{ml})$ was decreased with only 7 treatments within 7 weeks.

The treatment for hormonal balance usually is a long-term treatment and takes more time to achieve the results. However, in this case, we are very pleased with the results that came up in only 2 months only with acupuncture treatment.

According to the symptoms, the imbalanced and main affected organs in this case are Kidney and Spleen. Other affected organs are Liver and Heart.

Acupuncture has an excellent effect on the hormonal production, by removing phlegm and stasis from the meridians, recharging and vitalizing the affected organs, stimulating, regulating and harmonizing the hormones, the blood and the QI flow through the meridians, especially Spleen, Liver and Kidney meridian. Because the Liver is responsible for the emotions and the metabolism, along with balancing the hormones, acupuncture helps in reducing anxiety and stress, smoothing the emotions, helping manage the sleep and promoting tranquility and relaxation. Clinics (2021) "Family Tree Acupuncture And Herbal Medicine; Hormonal Imbalance" (2021) Arsovska et al. (2020a) Arsovska et al. (2020b)

Our goal with the further treatment is to keep these results normal, to normalize the FSH hormone and to maintain the mental as well as the overall health of the patient.

\section{CONCLUSION}

Acupuncture as part of the Traditional Chinese Medicine can effectively help the patients struggling with hormonal imbalances to balance and regulate the hormones 
and harmonize the metabolism, nervous, reproductive and endocrine system.

\section{REFERENCES}

Arsovska, B., Zhu, J., \& Kozovska, K. (2020a). Acupuncture Treatment In Female Patient With Infertility Due To Elevated Tsh., 7, 48-50.

Arsovska, B., Zhu, J., \& Kozovska, K. (2020b). CASE REPORT - ACUPUNCTURE TREATMENT IN FEMALE PATIENT PRESENTED WITH PRIMARY HYPOTHYROIDISM. International Journal of Research -GRANTHAALAYAH, 8(6), 71-74. Retrieved from https://dx.doi.org/ 10.29121/granthaalayah.v8.i6.2020.427 10.29121/granthaalayah.v8.i6.2020.427

Clinics, G. (2021). ondon; Chinese Medicine For Hormonal Imbalance; Traditional Chinese Medicine Blog. Retrieved from Www.Cmblog.Co.Uk

Family Tree Acupuncture And Herbal Medicine; Hormonal Imbalance. (2021). Retrieved from Www.Familytreeacupuncture.Com.Au 